\title{
Ingestão de Cafeína Como Estratégia Ergogênica no Esporte: Substância Proibida ou Permitida?
}

\section{"Carta ao Editor" referente ao artigo:}

"Diretrizes da Sociedade Brasileira de Medicina do Esporte: modificações dietéticas, reposição hídrica, suplementos alimentares e drogas: comprovação de ação ergogênica e potenciais riscos para a saúde". Rev Bras Med Esporte 2009;15:1-12.

\author{
Leandro Ricardo Altimari' \\ 1. Centro de Educação Física e Esporte. Universidade Estadual de Londrina, Londrina, PR, Brasil.
}

\section{Endereço para correspondência:}

Prof. Dr. Leandro Ricardo Altimari - Departamento de Educação Física - Universidade Estadual de Londrina - Rodovia Celso Garcia Cid, Pr 445 km 380 - Campus Universitário, Cx. Postal 6001 - 86051-990 - Londrina, PR - Brasil - E-mail: altimari@uel.br

Recentemente, a Sociedade Brasileira de Medicina do Esporte (SBME) atualizou suas diretrizes publicadas em 2003 sobre "Modificações dietéticas, reposição hídrica, suplementos alimentares e drogas: comprovação de ação ergogênica e potenciais riscos para a saúde"(1). Nesta atualização os autores relatam que "Substâncias antes permitidas, que foram incluídas no programa de monitoramento de 2008, portanto atualmente proibidas são: bupropiona, cafeína, fenilefrina, fenilpropranolamina, pipradol, pseudoefedrina, sinefrina". Contudo, acreditamos que os autores tenham cometido um equívoco, uma vez que essa afirmação não procede, em particular no que se refere à cafeína, tema abordado nesta carta.

Nos últimos anos, a ingestão de cafeína tem sido utilizada como estratégia ergogênica no esporte ${ }^{(2)}$, previamente à realização de exercícios físicos aeróbios ${ }^{(3-5)}$, e anaeróbios ${ }^{(6-8)}$, com o intuito de protelar a fadiga e, consequentemente, melhorar o desempenho físico. Neste sentido, os achados até o presente momento têm apontado a cafeína como um eficiente agente ergogênico em exercícios de diferentes naturezas ${ }^{(2-8)}$. Ressalta-se, entretanto, que a dosagem de cafeína é fator determinante na melhora do desempenho físico, pois o desencadeamento das respostas fisiológicas e metabólicas parece estar atrelado à quantidade ingerida ${ }^{(3,9)}$. Assim, embora doses de 3 a $10 \mathrm{mg} \cdot \mathrm{kg}^{-1}$ de peso corporal de cafeína possam melhorar o desempenho físico em exercícios físicos de diferentes naturezas, o intervalo ótimo sugerido é de 3 a $6 \mathrm{mg} \mathrm{kg}^{-1}$ de cafeína pura ${ }^{(3-6)}$.

\section{REFERÊNCIAS}

1. Rodrigues T, Meyer F, Zogaib P, Lazzoli JK, Magni JRT, Marins JCB, et al. Modificações dietéticas, reposição hídrica, suplementos alimentares e drogas: comprovação de ação ergogênica e potenciais riscos para a saúde. Rev Bras Med Esporte 2009;15:1-12.

2. Paluska SA. Caffeine and exercise. Curr Sports Med Rep 2003;2:213-9.

3. Graham TE. Caffeine and exercise: metabolism, endurance and performance. Sports Med 2001;31:785-807.

4. Doherty M, Smith PM. Effects of caffeine ingestion on exercise testing: a meta-analysis. Int J Sports Nutr Exerc Metabolism 2004;14:626-46.

5. Altimari LR, Melo JC, Trindade MCC, Cyrino ES, Tirapegui JO. Cafeína e exercício físico aeróbio. Nutrire 2006;31:79-96.

6. Altimari LR, Moraes AC, Tirapegui JO, Moreau RLM. Caffeine and performance in anaerobic exercise. Braz J Pharm Sci 2006;42:17-27.

7. Davis JK, Green JM. Caffeine and anaerobic performance: ergogenic value and mechanisms of action. Sports Med 2009;39:813-32.
A utilização indiscriminada de cafeína por parte de atletas, no início da década de 1980, com objetivo de melhorar o desempenho atlético, fez com que esta substância fosse incluída na lista de substâncias proibidas do Comitê Olímpico Internacional (COI), que estipulou valor limítrofe de $15 \mu \mathrm{g} / \mathrm{mL}$ de cafeína na urina para caso positivo de doping ${ }^{(10,11)}$. Porém, o uso de cafeína somente tornou-se evidente a partir dos Jogos Olímpicos de Los Angeles (1984), quando alguns membros da equipe de ciclismo dos Estados Unidos declararam publicamente terem usado esse alcalóide como estimulante durante as competições, o que fez com que o COl alterasse o valor limítrofe para $12 \mu \mathrm{g} / \mathrm{mL}$ de cafeína na urina para caso positivo de doping ${ }^{(3,9,11)}$.

Até final do ano de 2003, a cafeína fazia parte da lista de substâncias proibidas pela Agência Mundial Anti-Doping (WADA), na classe de estimulantes (A) e o limite estipulado para caso positivo de doping até aquele momento era de $12 \mu \mathrm{g} / \mathrm{mL}$ de cafeína na urina ${ }^{(5,6)}$. Contudo, devido às dificuldades de se estabelecer um valor limítrofe, desde o ano de 2004 a cafeína foi incluída junto com outras substâncias em um programa de monitoramento da WADA, não sendo essa considerada substância proibida, condição esta que se estende até os dias atuais ${ }^{(12)}$.

Vale ressaltar que, mesmo não sendo uma substância proibida pela WADA, estudos de acompanhamento realizados após a retirada da cafeína da lista de substâncias proibidas não observaram aumento significante no consumo da mesma no meio esportivo ${ }^{(13,14)}$.

\section{Prezado Prof. Dr. Leandro Ricardo Altimari}

Agradecemos sua correspondência e colaboração manifestada em sua carta sobre o equívoco na inclusão da cafeina no grupo de substâncias proibidas em nossa publicação "Diretrizes da Sociedade Brasileira de Medicina do Esporte - Modificações dietéticas, reposição hídrica,

suplementos alimentares e drogas: comprovação de ação ergogênica e potenciais riscos para a saúde" (Rev Bras Med Esporte 2009;15:1-12), observação que está perfeitamente correta.

Temos a informar que esse fato já havia sido observado por outros membros de nosso Corpo Editorial e que naquela ocasião já foi sugeri-
8. Astorino TA, Roberson DW. Efficacy of acute caffeine ingestion for short-term high-intensity exercise performance: a systematic review. J Strength Cond Res 2010;24:257-65.

9. Sinclair CJ, Geiger JD. Caffeine use in sports. A pharmacological review. J Sports Med Phys Fitness 2000;40:71-9.

10. Delbeke FT, Debackere M. Caffeine: use and abuse in sports. Int J Sports Med 1984;5:179-82

11. Rogers CC. Caffeine. Sports Med 1985;13:38-40.

12. WADA. World Anti Doping Agency. The 2010 prohibited list international standard. Disponivel em: http:// www.wada-ama.org/en/World-Anti-Doping-Program/. Acesso em: 07 fevereiro 2010.

13. Van Thuyne W, Roels K, Delbeke FT. Distribution of caffeine levels in urine in different sports in relation to doping control. Int J Sports Med 2005;26:714-8.

14. Van Thuyne W, Delbeke FT. Distribution of caffeine levels in urine in different sports in relation to doping control before and after the removal of caffeine from the WADA doping list. Int J Sports Med 2006;27:745-50. do que fosse informado aos leitores a correção dessa informação, o que aproveitamos para fazer nesta oportunidade, e sugerido que já fosse feita atualização daquele texto já contemplando as novas determinações da WADA para o ano de 2010, o que já foi providenciado.

Mais uma vez agradecemos sua colaboração e o cumprimentamos pelo olhar atento à nossa revista e pronta atitude em colaborar para meIhoria da RBME.

Atenciosamente,

Prof. Dr. Arnaldo José Hernandez

Editor-Chefe da RBME 